\title{
Simulation Model of Wind Turbine Power Control System with Fuzzy Regulation by Mamdani and Larsen Algorithms
}

\author{
Ghada Adel Aziz \\ Department of Electromechanics Engineering/University of Technology \\ Email:pghadasama@yahoo.com
}

(Received 19 June 2016; accepted 22 January 2017)

https://doi.org/10.22153/kej.2017.01.003

\begin{abstract}
The aim of this work is to create a power control system for wind turbines based on fuzzy logic. Three power control loop was considered including: changing the pitch angle of the blade, changing the length of the blade and turning the nacelle. The stochastic law was given for changes and instant inaccurate assessment of wind conditions changes. Two different algorithms were used for fuzzy inference in the control loop, the Mamdani and Larsen algorithms. These two different algorithms are materialized and developed in this study in Matlab-Fuzzy logic toolbox which has been practically implemented using necessary intelligent control system in electrical engineering and renewable energy concepts.

A comparison was done to access the functionality of the developed power control system of fuzzy logic and classical control system with PID - control. It can be concluded that the power control system of fuzzy logic allows to accurately maintain production under the control target function for each work area. When switching operation of wind turbines, it has the distinction that from $13.5 \mathrm{~m} / \mathrm{s}$ to another wind velocity value, there is no overshoot and a typical of classical control systems, and when the wind velocity $\mathrm{V}$ is less than $13.5 \mathrm{~m} / \mathrm{s}$, the pitch angle of the blades should be slightly greater than zero, and if it has increased by $5^{\circ}$, then blade length should be minimal as possible. Simulation program proved the possibility of effective power regulation for the large wind turbines controller fuzzy type on the basis of knowledge production "if - then" rules, which were shown to be effective on these wind turbines control.
\end{abstract}

Keywords: Mamdani and Larsen algorithms fuzzy inference, Matlab Fuzzy Logic ,Fuzzy-PID controllers, Wind turbine.

\section{Introduction}

The development of wind power, combined with energy conservation measures in the field of wind energy in 2030 will be able to provide $29 \%$ of electricity demand in the world, because the statistical view has been showed this forecasting during the last 15 years especially the last one in the global annual installed wind capacity in 2015 has been reached to 63,013 MW.[ 1 ]. In recent years many researchers discuss the characteristics of the wind turbine and focus on the latest advances in wind energy modeling aerodynamic and wind control with methods of nonlinear, fuzzy and forecasting [2].
The aim is to control the angle of the wind turbine blades at different wind speeds and with the set of Matlab/ Simulink simulation environment software development controller for stable operation. Obviously fuzzy PID controller and fuzzy PI controller to produce better than these comparisons after modeling.[3]. Design synthesis of the vector control system yawn Fuzzy PID controller, system modeling using Matlab modeling software, and taking simulation test. Comparing the simulation curves with the general PID control and fuzzy PID control section, the result show that the synthesis of a fuzzy PID control system has a high performance stability [4]. 
A specific fuzzy controller takes into account both wind speed and errors acceptable correlation to obtain maximum performance efficiency. The turbine is able to maintain its power output around its nominal value, and at the same time maintain its rotation about the vertical axis of the movement system meaningless. Careful simulation tests to evaluate the effectiveness of the proposed system [5].

Application of the theory of fuzzy sets for control tasks Mamdani process in 1975 was carried out for the first time year. Mamdani has created a fuzzy controller for controlling the steam generator. Currently used in the Classical proportional plus integral plus derivative (PID) controllers are still the most widely adopted method in industry for various control applications, due to their simple structure, ease of design, and low cost in implementation, the best, nonlinear and adaptive management. Also, fuzzy sets of input and output variables should increase in order to have a better accuracy with more corrective action formulae .[6]. The Mamdanitype FIS uses the technique of defuzzification of a fuzzy output and has output membership functions, and the Mamdani method needs more computation time, and the results have fewer errors, but it is less flexible in system design as compared with others like Sugeno method ,because Sugeno can be integrated with ANFIS tool to optimize the output and has no output membership function [7].

The load system is simulated in the MATLAB/SIMULINK and the performance operated by PI Controller and Fuzzy logic controllers (FLC ) are compared and analyzed with 25-rules base stores the linguistic control rules which required by rule evaluator [8], and the decision making task can be carried on through a Fuzzy Logic Controller optimized Algorithm, which able to tune FLCs parameters minimizing, at the same time, the number of fuzzy rules may be Having three parameters for each triangular MF with three input and one output for the FLC, with The FIS composed by 27 rules is thus characterized the two FIS in the proposed FLC, will account for 126 real bounded values and it has got a good performance comparison [9].

A fuzzy inference system may have different shapes like triangular, trapezoidal, Gaussian, etc., the effect of membership function is studied and evaluated in the fuzzy logic controller and the performance comparison with a three different types of membership function in fuzzy logic controller [10], and for each membership functions In a fuzzy scale of five linguistic states of triangular type can be mapped into the values of Negative "Large (NL), Negative Small (NS), Zero Error (ZE), Positive Small (PS) and Positive Large (PL) With the 5MFs 25 rules" which are formed and applied to the system used [11].

The Wind Power Vestas V27 - 225 is the Model wind turbine suggested with a Start-up wind speed: $3,5 \mathrm{~m} / \mathrm{s}$, Nominal wind speed: $14 \mathrm{~m} / \mathrm{s}$ and Maximum wind speed: $25 \mathrm{~m} / \mathrm{s}$ and the tail is able to turn the head to the wind wheel in the direction of the wind at his rejection at $10-20^{\circ}$.are its characteristics [12].

\section{The Mathematical Modulation}

The mechanical power is calculated by understanding the calculation of the mechanical power through the wind turbines, which the Wind energy is transformed to mechanical power then it is converted to electrical power [13] :

The force experienced.

$\mathrm{F}=0.5 \rho \mathrm{AV}^{2}$

And the rotor torque equation is given by $\mathrm{T}=0.5 \rho \mathrm{AV}^{2} \mathrm{R}$

Where here $\mathrm{R}=$ rotor radius.

According to well-known relations aerodynamic moment $\mathbf{M}_{\mathbf{p}}$ and power $\mathbf{P}_{\mathbf{p}}$ propeller are uniquely determined by the frequency of rotation $\mathbf{n}$ and wind speed $\mathbf{V}$ (c considering the pitch angle of the blade) [14]:

$\mathrm{M}_{\mathrm{p}}=0.5 \mathrm{M} \pi \mathrm{R}^{3} \rho \mathrm{V}^{2}$

Where $\mathrm{n}=\frac{\omega}{2 \pi} \quad ; \omega=\mathrm{z} \frac{V}{R} \quad ; \mathrm{p}_{\mathrm{p}}=\mathrm{M}_{\mathrm{p}} \omega$

Taken in to account the $\mathbf{C}_{\mathbf{p}}$ is the performance coefficient of the turbine, $\rho$ is the air density $\left(\mathrm{Kg} / \mathrm{m}^{3}\right)$, A is the turbine swept area $\left(\mathrm{m}^{2}\right) . \mathrm{V}$ is the wind speed $(\mathrm{m} / \mathrm{s})$, which going to find the mechanical output power of the turbine (W) as [7]:

$\mathrm{P}_{\mathrm{p}}=0.5 \rho \mathrm{C}_{\mathrm{p}} \mathrm{A} \mathrm{V}^{3}$

$\mathrm{C}_{\mathrm{p}}$ Ratio determines the efficiency of wind energy depends on the design and the propeller, the rotor speed and wind speed. It is given by:

$\mathrm{C}_{\mathrm{p}}=0.5\left(\mathrm{z}-0.022 \alpha^{2}-5.6\right) \mathrm{e}^{-0.17 \mathrm{z}}$

\subsection{The Fuzzy Inference Mamdani Algorithm}

The rule base when the hypothesis of mutual independence of the variables is based on the rules of many inputs and one the output variable. In the fuzzy inference Mamdani algorithm, the rules are as follows [15]:

If $\boldsymbol{x}_{i}$ has $\boldsymbol{A}_{i 1}$ and $\boldsymbol{x}_{j}$ has $\boldsymbol{A}_{i j}$ and $\boldsymbol{x}_{m}$ has

$\boldsymbol{A}_{\boldsymbol{i} m}$, then y has $\boldsymbol{B}_{i}, \mathrm{i}=1,2,3, \ldots \ldots . \mathrm{n} \quad$...(6) 
the Cartesian product of fuzzy sets is given by :

$\mu_{A_{i 1} \times A_{i 2}}\left(x_{1}, x_{2}\right)=\min \left\{\mu_{A_{i 1}}\left(x_{1}\right), \mu_{A_{i 2}}\left(x_{2}\right)\right\}$

The Fuzzy implication - operation minconjunctions; T-rate - min-conjunctions; Accumulation of activated prisoners' rights - maxdisjunction; Bringing to the definition - centroid method, the center of gravity method. The Mamdani algorithm has great robustness, clarity inference, but it creates a deformation nonlinear function accessories background $\alpha$-section of the top, and the operation "center of mass" actually uses the median, that is not the purpose of fuzzy compiler model. Well suitable for modulating control, without the abrupt transitions between the values of the output variables.

\subsection{The Fuzzy Inference Larsen Algorithm}

The rule base of the rules is based on many inputs and many output variables. In fuzzy inference Larsen algorithm, the rules are as follows [15]:

If $x_{i}$ has $A_{i 1}$ and $x_{j}$ has $A_{i j}$ and $x_{m}$ has $A_{i m}$, then $y_{1}$ has $B_{i 1}$ and $y_{k}$ has $B_{i k}$ and

$y_{p}$ has $B_{i p} \quad \mathrm{i}=1,2,3, \ldots . n$

the Cartesian product of fuzzy sets is given by :

$$
\mu_{R}(\mathrm{x}, \mathrm{y})=\mu_{A}(\mathrm{x}) \cdot \mu_{B}(\mathrm{y})
$$

The Fuzzy implication- fuzzy multiplication of species;-T-rate - min-conjunction; Storage Activated opinions - max-disjunction. Bringing to the definition - for choosing a method of method of defuzzification.

The findings of function supplies shrink, the base is not changes due to what has sharp transition between managers signals, robustness and adaptability. Well suitable for rapid -"Hard" regulation.

\section{Fuzzy Control Rules and Controller Models Simulation in MATLAB FUZZY LOGIC}

A power control V-27 wind turbine, which is a model in Matlab Simulink program presented, fuzzy control power turbine system algorithm is used and consists of the transformation of the variables of fuzzy logic controller (wind speed and the angle between the position of the nacelle and the wind direction) in its output variables (the angle of attack of the blade, the blade length, angle of the nacelle) with the following interrelated processes:
- Conversion of quantities of clear physical variables derived from measuring wind sensor parameters, the dimensionless linguistic variables; - Processing of linguistic variables according to the rule base;

- Conversion of the output of the dimensionless variables of fuzzy controller into physical control actions

In the MATLAB software package FUZZY LOGIC. The model consists of the following units: 2 input variables, rule base and 3 output variables as shown in fig. 1 regulator functions in terms of the rules of "if - then " and thus can enforce a friendly and understanding person representation of knowledge.

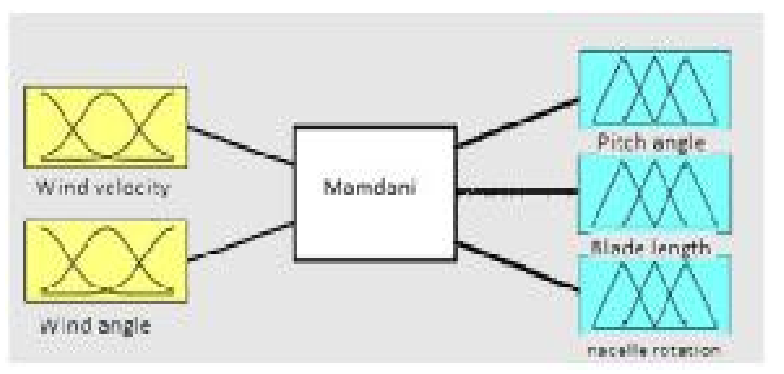

Fig. 1. Fuzzy control model with the algorithm Mamdani for all output values plots on the MATLAB GUI of a fuzzy logic controller.

Algorithm used as a fuzzy implication operation uses "MINIMUM", aggregation clipped term set of preconditions produced "Maximum" operation. Bringing to the definition that is made a method of center of gravity, which is applied to all control loops.

As shown in fig. 2 the power control models with different fuzzy inference algorithms. In the first controller has two output variables (the angle of attack and blade length) for the fuzzy inference which applies an algorithm Mamdani. In the second regulator output variable is the rotation of the nacelle, for fuzzy inference of this Larsen variable algorithm is used.

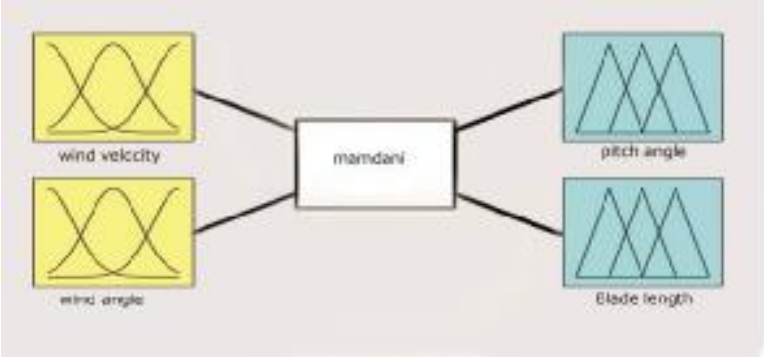




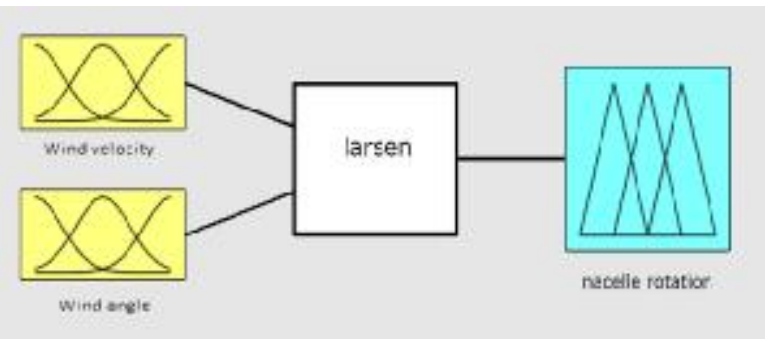

Fig. 2. Models regulators for all output values plots on the MATLAB GUI of a fuzzy logic controller with different output algorithms.

Accurate speed and wind direction is referred to as «Inl». AT Block «Input MF» shows the membership function of each term- a plurality of input variables. There is a clear statement of the value of the variable in all functions Facilities, which are the sum of the final curves. At finally calculated features - accessory of each term set. In other words, as far as the entrance is a clear value is "working" "High", "very high", "high mission". Further, the non-zero term-sets used in the «Rule» blocks as shown in fig 3 .

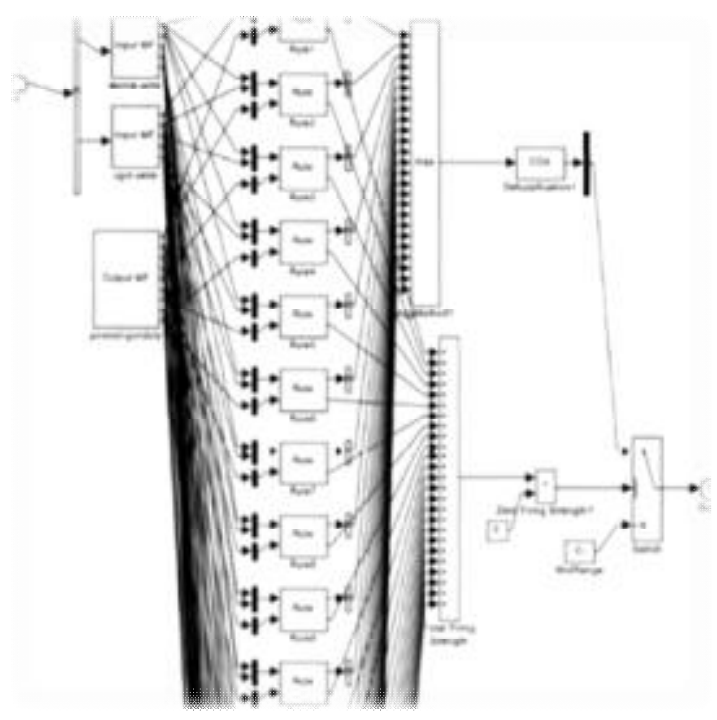

Fig. 3. Block diagram of a non-rigid type regulator.

To indicate the requirements or conditions used "if" indicator output or conclusion - "then". It is usually prepared from a special knowledge or heuristics and appears as a set of If-Then rules. The rules are based on concepts of fuzzy inference and linguistic variables assumptions and implications . Fuzzy sets and fuzzy operator is the word of the materials and the fuzzy logic. Usually associated with the fuzzy rule is expressed as:

IF $x$ is $N$ THEN $y$ is $M$
Where $\mathrm{x}$ and $\mathrm{y}$ are fuzzy variables and the fuzzy values are $\mathbf{N}$ and $\mathbf{M} .[16]$, In this wind turbine system , the rule base consists of 16 rules, which has the form:

\section{If wind velocity $\mathbf{V}$ has $N$ and $\psi$ angle has $Z$, Then $\alpha$ has $Z$ and $L_{\text {blade }}$ has $L$ and $d \psi$ has $Z$;}

According to the rules, inference method above and the fuzzy variable of input and output, The fuzzy control rules are obtained in table 1 as follow:

Table 1,

Rules table of fuzzy control.

\begin{tabular}{|c|c|c|c|c|}
\hline $\begin{array}{l}\mathrm{V} \\
\psi\end{array}$ & $\mathbf{N}$ & $\mathbf{H}$ & V H & $\mathrm{Cr}$ \\
\hline \multirow[t]{2}{*}{$\mathbf{Z}$} & $\alpha=Z$ & $\alpha=\mathrm{M}$ & $\alpha=\mathrm{L}$ & $\alpha=\mathrm{L}$ \\
\hline & $\begin{array}{l}\mathrm{L}_{\text {blade }}=\mathrm{L} \\
\mathrm{d} \psi=\mathrm{Z}\end{array}$ & $\begin{array}{l}\mathrm{L}_{\text {blade }}=\mathrm{Z} \\
\mathrm{d} \psi=\mathrm{Z}\end{array}$ & $\begin{array}{l}\mathrm{L}_{\text {blade }}=\mathrm{Z} \\
\mathrm{d} \psi=\mathrm{Z}\end{array}$ & $\begin{array}{l}\mathrm{L}_{\text {blade }}=\mathrm{Z} \\
\mathrm{d} \psi=\mathrm{PL}\end{array}$ \\
\hline \multirow[t]{2}{*}{$\mathbf{S}$} & $\alpha=Z$ & $\alpha=S$ & $\alpha=\mathrm{M}$ & $\alpha=\mathrm{L}$ \\
\hline & $\begin{array}{l}\mathrm{L}_{\text {blade }}=\mathrm{L} \\
\mathrm{d} \psi=\mathrm{Z}\end{array}$ & $\begin{array}{l}\mathrm{L}_{\text {blade }}=\mathrm{Z} \\
\mathrm{d} \psi=\mathrm{Z}\end{array}$ & $\begin{array}{l}\mathrm{L}_{\text {blade }}=\mathrm{Z} \\
\mathrm{d} \psi=\mathrm{Z}\end{array}$ & $\begin{array}{l}\mathrm{L}_{\text {blade }}=\mathrm{Z} \\
\mathrm{d} \psi=\mathrm{PL}\end{array}$ \\
\hline \multirow[t]{2}{*}{$\mathbf{M}$} & $\alpha=\mathrm{Z}$ & $\alpha=\mathrm{S}$ & $\alpha=\mathrm{M}$ & $\alpha=\mathrm{L}$ \\
\hline & $\begin{array}{l}\mathrm{L}_{\text {blade }}=\mathrm{L} \\
\mathrm{d} \psi=\mathrm{NS}\end{array}$ & $\begin{array}{l}\mathrm{L}_{\text {blade }}=\mathrm{Z} \\
\mathrm{d} \psi=\mathrm{Z}\end{array}$ & $\begin{array}{l}\mathrm{L}_{\text {blade }}=\mathrm{Z} \\
\mathrm{d} \psi=\mathrm{Z}\end{array}$ & $\begin{array}{l}\mathrm{L}_{\text {blade }}=\mathrm{Z} \\
\mathrm{d} \psi=\mathrm{PS}\end{array}$ \\
\hline \multirow[t]{2}{*}{$\mathbf{L}$} & $\alpha=\mathrm{L}$ & $\alpha=\mathrm{Z}$ & $\alpha=\mathrm{S}$ & $\alpha=\mathrm{L}$ \\
\hline & $\begin{array}{l}\mathrm{L}_{\text {blade }}=\mathrm{L} \\
\mathrm{d} \psi=\mathrm{NL}\end{array}$ & $\begin{array}{l}\mathrm{L}_{\text {blade }}=\mathrm{Z} \\
\mathrm{d} \psi=\mathrm{Z}\end{array}$ & $\begin{array}{l}\mathrm{L}_{\text {blade }}=\mathrm{Z} \\
\mathrm{d} \psi=\mathrm{Z}\end{array}$ & $\begin{array}{l}\mathrm{L}_{\text {blade }}=\mathrm{Z} \\
\mathrm{d} \psi=\mathrm{Z}\end{array}$ \\
\hline
\end{tabular}

Model wind turbine power control system in the application of fuzzy inference algorithm is shown in fig. 4. As described above, This algorithm Mamdani and Larsen, The inputs of a fuzzy controller type are (from top to bottom as shown in fig.4):

Wind speed, and the value created by the dynamic wind model, and the angle of misalignment between the position of the nacelle and the wind direction. And the value created by the sum of the angle of the wind direction and the angle of rotation of the nacelle.

Controller outputs are:

Blade angle of attack. Defines the utilization of wind energy; the length of the blade to change the swept area of the wind wheel. Area, and the angle of rotation of the gondola. Summing with the wind direction angle, determines angle error.

The magnitude of the wind angle, obtained from the dynamic wind patterns, folded to the size of the angle of rotation of the nacelle. From the resulting angle of misalignment between the position and the direction of the nacelle wind calculated projection perpendicular to the plane of the propeller. The value of working in a cube of the wind is supplied to the fourth input. 


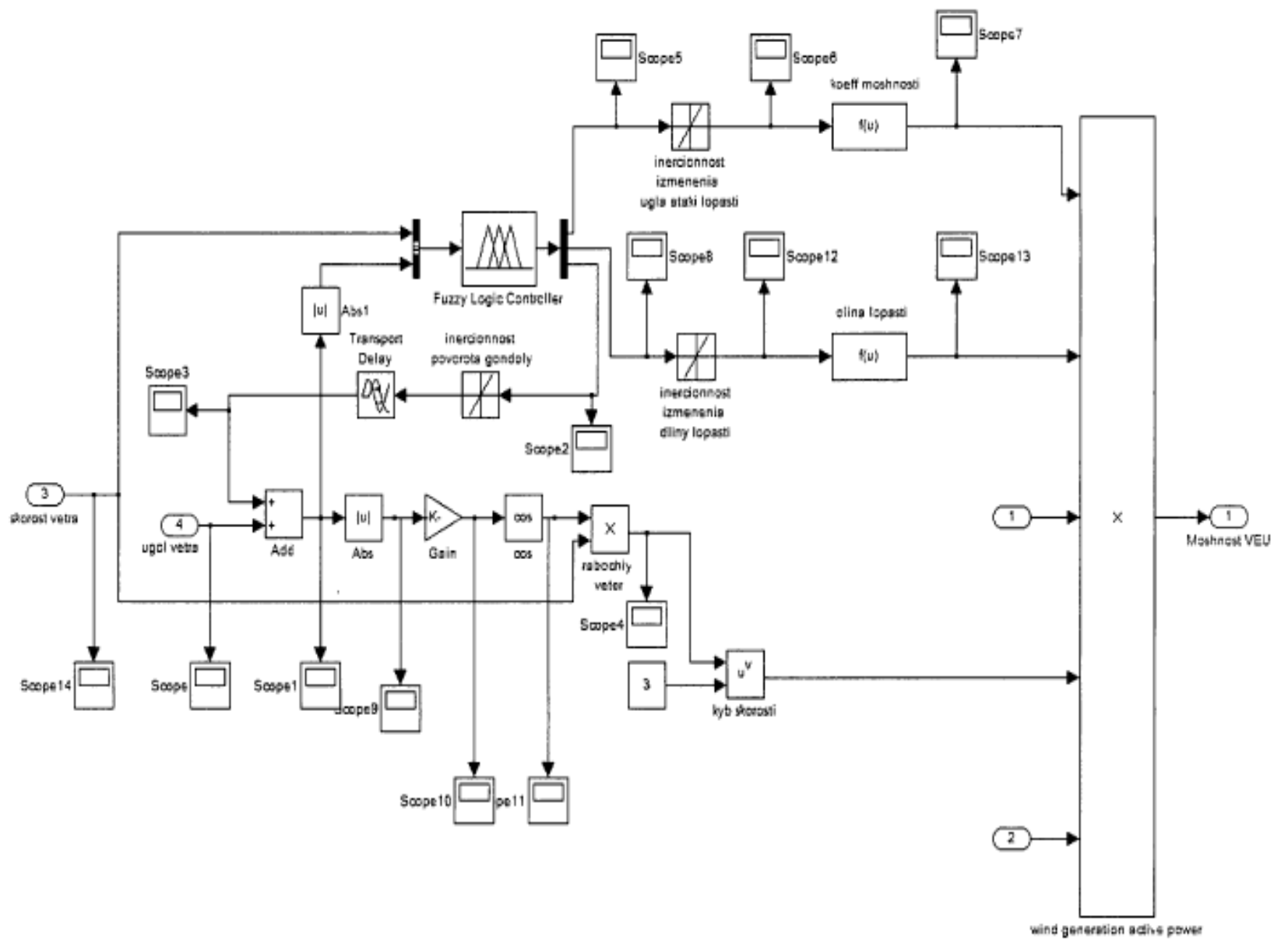

Fig. 4. The power control system structure of the wind turbine with a fuzzy inference algorithm.

\section{Simulation Results}

Design of fuzzy model begins with the definition of the functions supplies for the nonzero terms, linguistically characterize input and output variables . Input variables - wind speed V and the $\psi$ angle between the wind direction and

\begin{tabular}{lllll}
\hline wind velocity $\mathbf{V}$ & $\mathbf{N}$ & $\mathbf{H}$ & $\mathbf{V H}$ & $\mathbf{C} \boldsymbol{\Gamma}$ \\
\hline 3.5 & 1 & 0 & 0 & 0 \\
5 & 1 & 0 & 0 & 0 \\
15 & 1 & 0,5 & 0 & 0 \\
20 & 0 & 0,5 & 1 & 0,5 \\
25 & 0 & 0 & 0,5 & 1 \\
\hline
\end{tabular}

the position of the nacelle. In this way, you must define the membership function of the variable term-sets $\mathrm{V}$ wind speed range from 3 to $25 \mathrm{~m} / \mathrm{s}$. Membership functions term set wind speed are shown in fig.5. the membership functions of the variable the wind velocity Schedule.

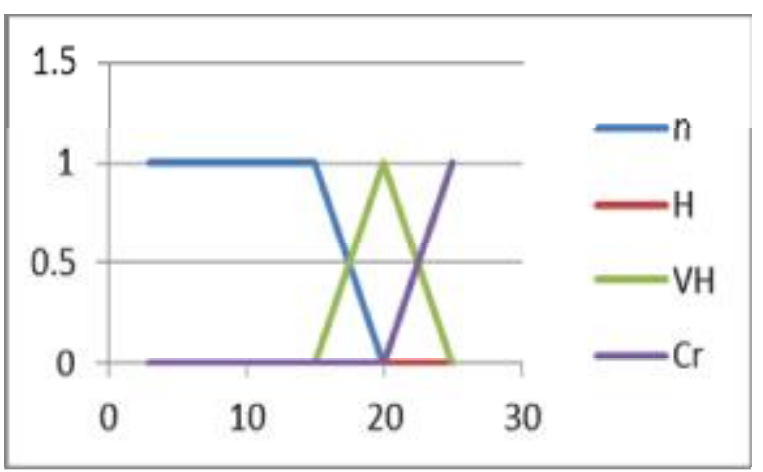

Fig. 5. The membership functions of the variable the wind velocity Schedule. 
The second input value of the controller model is the angle $\psi$ between the position of the nacelle and the wind direction. Fig. 6. show that the

\begin{tabular}{lllll}
\hline $\begin{array}{l}\text { angle nacelle } \\
\text { deg }\end{array}$ & $\mathbf{Z}$ & $\mathbf{S}$ & $\mathbf{M}$ & $\mathbf{L}$ \\
\hline 0 & 1 & 0 & 0 & 0 \\
20 & 0 & 1 & 0 & 0 \\
45 & 0 & 0 & 0.5 & 0 \\
60 & 0 & 0 & 0 & 0.5 \\
90 & 0 & 0 & 0 & 1 \\
\hline
\end{tabular}

numerical values of the membership functions of the variable term-sets "Angle $\psi \gg$ in the range (0; 90).

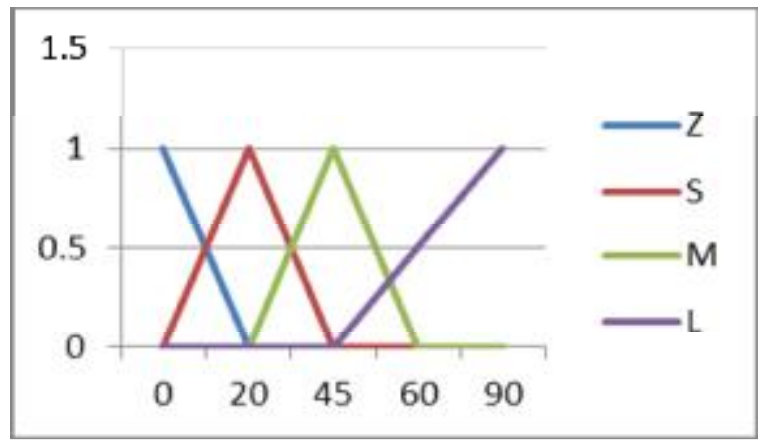

Fig. 6. The membership functions of the variable term-sets "Angle $\psi$ ".

Defined membership function sets the variable-term "Draft" in the range $(0 ; 45)^{\circ}$. Fig.7

\begin{tabular}{llllll}
\hline $\begin{array}{l}\text { pitch angle } \\
\text { deg }\end{array}$ & $\mathbf{Z}$ & $\mathbf{S}$ & $\mathbf{M}$ & $\mathbf{N}$ & $\mathbf{L}$ \\
\hline 0 & 1 & 0 & 0 & 0 & 0 \\
3 & 0 & 0.5 & 0 & 0 & 0 \\
5 & 0 & 1 & 0 & 0 & 0 \\
10 & 0 & 0 & 0.5 & 0 & 0 \\
15 & 0 & 0 & 1 & 0 & 0 \\
20 & 0 & 0 & 0.5 & 0 & 0 \\
25 & 0 & 0 & 0 & 1 & 0 \\
30 & 0 & 0 & 0 & 0 & 0.5 \\
45 & 0 & 0 & 0 & 0 & 1 \\
\hline
\end{tabular}

the Schedule attack membership functions is presented.

Fig. 7. The membership functions of the variable "Angle $\alpha$ ".

Fig. 8. Defined membership function sets the variable-term "Blade length $L$ " in the range of $(0,1.3) \mathrm{m}$.

\begin{tabular}{lllll}
\hline Blade length $\mathbf{~ m}$ & $\mathbf{Z}$ & $\mathbf{S}$ & $\mathbf{M}$ & $\mathbf{L}$ \\
\hline 0 & 1 & 0 & 0 & 0 \\
0.1 & 0.5 & 0 & 0 & 0 \\
0.2 & 0 & 0.5 & 0 & 0 \\
0.4 & 0 & 1 & 0 & 0 \\
0.6 & 0 & 0.5 & 0 & 0 \\
0.7 & 0 & 0 & 0.5 & 0 \\
0.9 & 0 & 0 & 1 & 0 \\
1 & 0 & 0 & 0.5 & 0 \\
1.1 & 0 & 0 & 0 & 0 \\
1.2 & 0 & 0 & 0 & 0.5 \\
1.3 & 0 & 0 & 0 & 1 \\
\hline
\end{tabular}

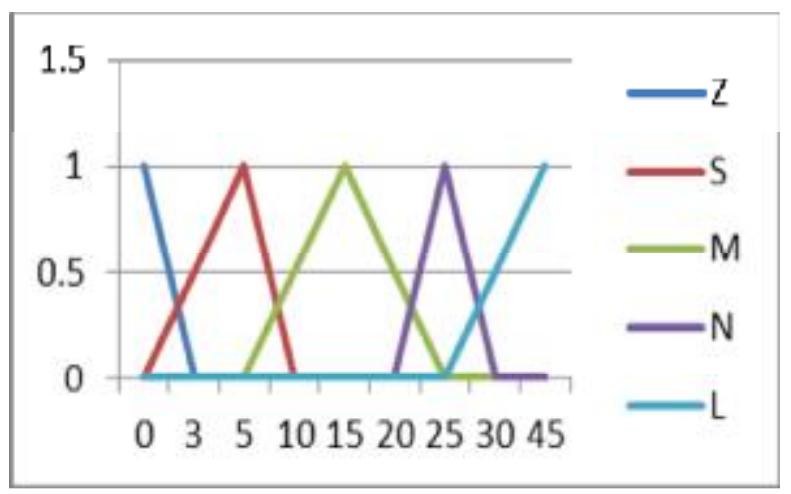

Fig. 8. The membership functions of the variable term "Blade length $L$ ".

Fig. 9 Defined membership function sets the variable term-angle rotating nacelle $\beta$ Tom in the range of $(-90,90)^{\circ}$ :

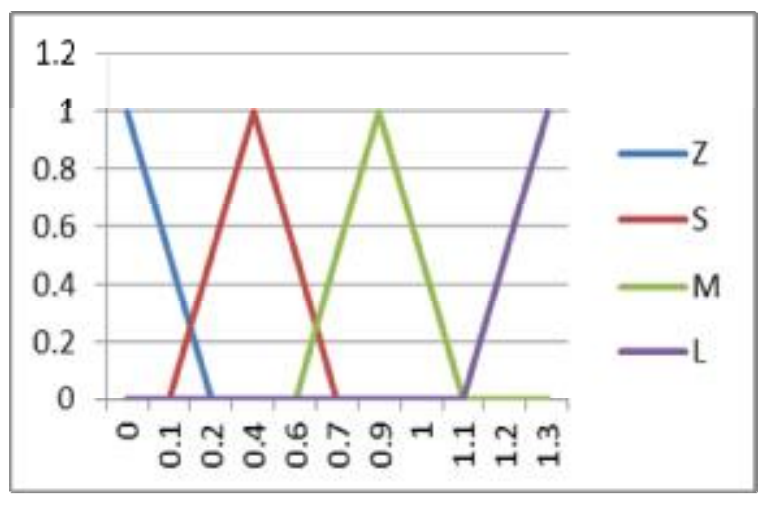




\begin{tabular}{llllll}
\hline $\boldsymbol{\beta}$ & $\mathbf{N L}$ & $\mathbf{N S}$ & $\mathbf{Z}$ & $\mathbf{P S}$ & $\mathbf{P L}$ \\
\hline-90 & 1 & 0 & 0 & 0 & 0 \\
-80 & 0,66 & 0 & 0 & 0 & 0 \\
-70 & 0,33 & 0,33 & 0 & 0 & 0 \\
-60 & 0 & 0,66 & 0 & 0 & 0 \\
-50 & 0 & 1 & 0 & 0 & 0 \\
-40 & 0 & 0,66 & 0 & 0 & 0 \\
-30 & 0 & 0,33 & 0 & 0 & 0 \\
-20 & 0 & 0 & 0,33 & 0 & 0 \\
-10 & 0 & 0 & 0,66 & 0 & 0 \\
0 & 0 & 0 & 1 & 0 & 0 \\
10 & 0 & 0 & 0,66 & 0 & 0 \\
20 & 0 & 0 & 0,33 & 0 & 0 \\
30 & 0 & 0 & 0 & 0,33 & 0 \\
40 & 0 & 0 & 0 & 0,66 & 0 \\
50 & 0 & 0 & 0 & 1 & 0 \\
60 & 0 & 0 & 0 & 0,66 & 0 \\
70 & 0 & 0 & 0 & 0,33 & 0,33 \\
80 & 0 & 0 & 0 & 0 & 0,66 \\
90 & 0 & 0 & 0 & 0 & 1 \\
\hline
\end{tabular}



Fig. 9. The membership functions of the variable term-angle rotating nacelle $\beta$.

The mode that does not require power limitation of wind turbines, the angle of attack blades must match the optimum operating conditions. Fig.10 shows the variation of the pitch angle blade when using fuzzy controller type and PID - control. In this mode, it is necessary to maintain the pitch angle blade is equal to zero for the maximum utilization of wind energy. At fuzzy operation controller such as $\alpha=0.3^{\circ}$, with the functioning of PID - controller pitch angle blade changes slight range.

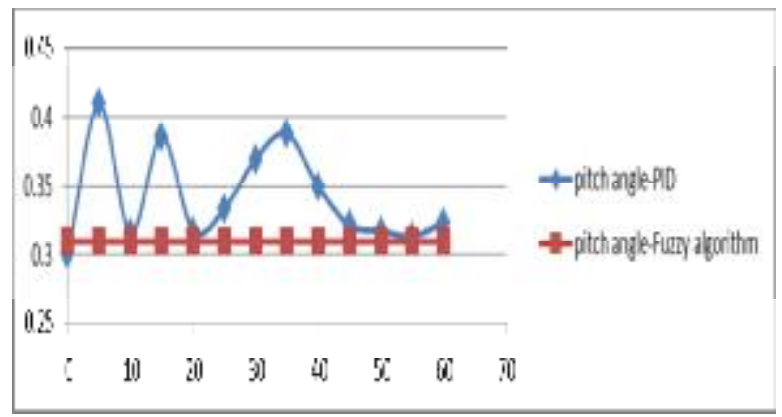

Fig. 10. The variation of the blade angle of attack (pitch angle) when using fuzzy controller type and PID - control.

The length of the additional blades of both types of regulators should maintained at the maximum value. It should be noted that the maximum value of the additional part of the blade length $\mathrm{dL}=0.5 \mathrm{~m}$ on fig. 11 . The mode that does not require limiting the power control loop length of the blade generates a command to maintain the maximum length to increase the swept area of the wind wheel. In operation, the controller of the fuzzy type increase in length of the blades is achieved "strong increase" command issued rules base. The graph shows that the length of the extra part of the blade is not equal maximum. This fact is explained by the form of the function Accessories-set term "blade length," which has a triangular view. the center of gravity method used to bring to the output values of the blade length, is capable of producing the maximum length for using membership functions of triangular form with vertex point $d L_{\max }$

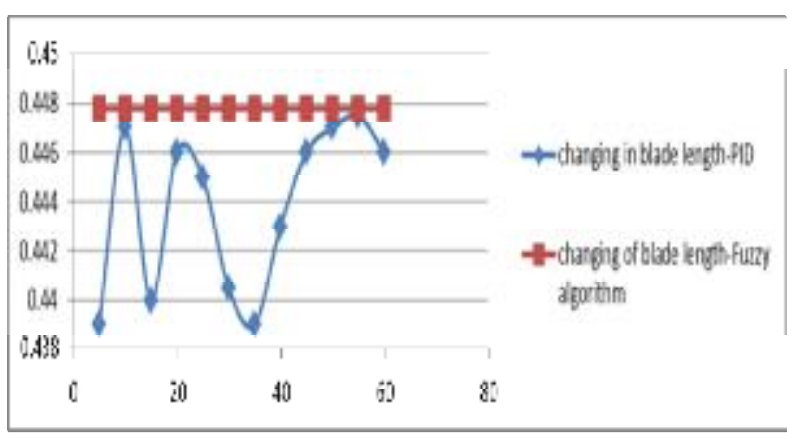

Fig. 11. the length of the additional parts of the blade.

In the low speed mode, the target wind control function Power is to develop the highest possible power. One of conditions for the maximum use of wind energy is the turn of the nacelle when the direction of the wind. Fig. 12. shows graphs changes in the $\beta$ nacelle angle. 


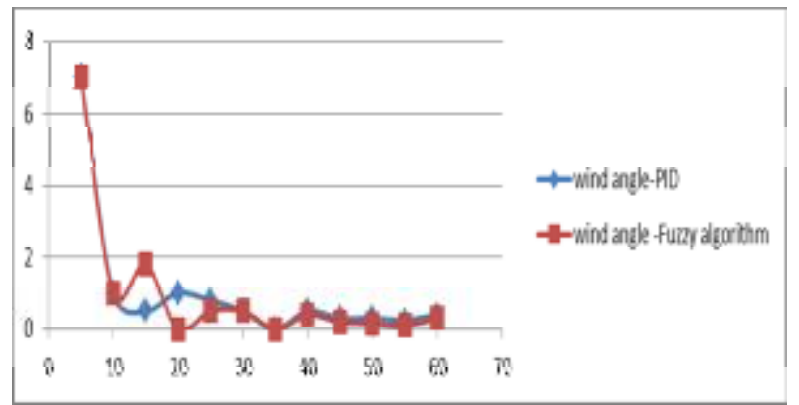

Fig. 12. graphs changes in the $\beta$ nacelle angle.

Rotate the nacelle both types of controllers is made the same way, due to the slow change in the wind direction and the effectiveness of the rotation of the nacelle to the maximum rate of wind energy is estimated as the angle of misalignment $\mathrm{W}$ between the position of the nacelle and the prevailing wind direction.

At Modern wind turbines of high power nacelle rotation is the purpose of maintaining the angle $\psi$ of less than $10^{\circ}$. At an angle $\psi<10^{\circ}$ rotation of the nacelle for high power wind turbines are not implemented due to continued low wind variations. Aspiration reduce the value of the angle to the value $\psi=0{ }^{\circ}$ continuous rotation of the nacelle It can be dangerous for the mechanical strength of the wind turbine.

The values of the angle of misalignment $\psi$ are shown in fig. 13. at this chart shows that up to $\mathrm{t}=$ 10 s. $\psi$ angles are increased to values of $10^{\circ}$, further angle decreases to $2^{\circ}$ and maintained at that level throughout the regulation time.



Fig. 13. Angle $\psi$ between the position of the nacelle and the prevailing wind direction $d \psi$

The capacity charts Wind turbines at a slow change in wind speed - «working slow» and fast change in the wind direction - «fast». Fig. 14 shows the power variation graphs of wind turbines, while the closest approximation to the maximum power regulator shows Larsen algorithm to change the angle of attack and blade length and algorithm Mamdani to rotate the nacelle.

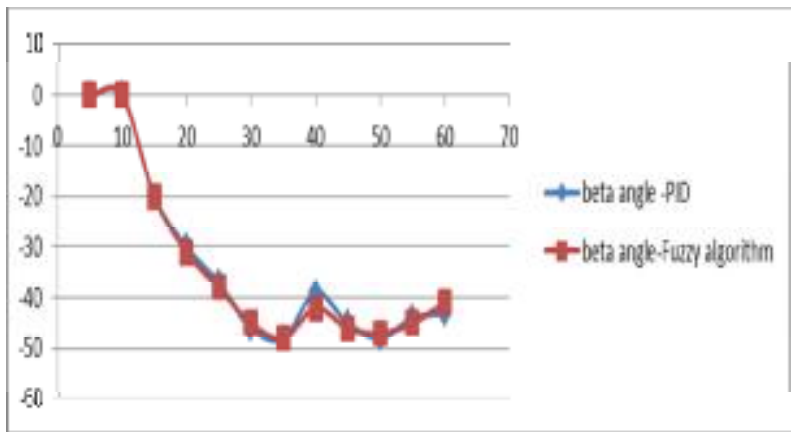

Fig. 14 the power variation graphs of wind turbines.

\section{Discussion}

When developing a model of the power control system based on fuzzy logic, which allows to use different algorithms for control loops. This model allows to experimentally validate the theoretical propositions to improve the efficiency of power control. The power control system of the wind turbine based on fuzzy logic, the change in pitch angle and blade length are rotating nacelle regulator output values on fuzzy logic.

The air density was adopted unchanged $\rho=$ $1.009 \mathrm{~kg} / \mathrm{m}^{3}$, and The increase in air temperature from $+15^{\circ}$ to $+30^{\circ}$ reduces power by about $5 \%$, and decrease with temperature $+15^{\circ}$ to $0^{\circ}$, It increases the power of the wind flow around 6\%. At constant air temperature change of atmospheric pressure from 770 to $730 \mathrm{~mm} \mathrm{Hg}$. reduces the flow rate of $7 \%$.

When a smooth change in the wind direction to pitch angle blade It maintained close to zero due to the high speed drive mechanisms for implementing the rotation of the blade. Thus, the use of fuzzy controller type allows you to maintain more accurate necessary pitch angle blade at low wind speeds mode. In an analysis of fig. 12 and fig. 13 get the following conclusion to $\mathrm{t}=10 \mathrm{sec} . \psi<10^{\circ}$, so the nacelle rotation is not performed but when $\psi>10^{\circ}$ rotation of the nacelle run loop and nacelle angles of rotation It can be seen in Fig. 12. One can argue about the correctness of the compiled rule base to rotate the nacelle and selected membership functions input and output values so $\psi<10^{\circ}$ over the entire range.

The result of good regulation power is achieved using a regulator with Larsen algorithm for all circuits. The application shows the remaining two regulators least favorable result, due to a smooth withdrawal process control 
signals Mamdani algorithm, not providing speed. The contour of the low power control algorithm Mamdani resource used for circuit with high resource used algorithm Larsen, and The results of calculations with fuzzy regulation showed that the power control system of fuzzy logic is most effective when using Larsen's algorithm for contour changes the pitch angle and blade length and Mamdani algorithm for contour turning the nacelle.

In this model, when the controller supports fuzzy type a $\alpha=0.3^{\circ}$, the rule base provides command "to set a value of zero.", and the pitch angle of the blade is constant throughout the control range, the functioning of the speed control loop is represented by the signal change rate limiting unit with the speed of rotation of the blade is limited to $8 \%$, and the rotation of the nacelle up to $5 \%$.

By comparing the results of the functioning of the developed power control system of fuzzy logic and classical control system with PID - control, it can be shown that the power control system of fuzzy logic allows to accurately maintain production under the control target function for each work area. and when switching operation of wind turbines from $13.5 \mathrm{~m} / \mathrm{s}$ to another wind velocity there is no overshoot, typical of classical control systems, and the mode to maintain maximum utilization of wind energy capacity is observed increase by an average of $5 \%$, in the power limit mode - achieved a close match the nominal power.

\section{Conclusions}

1. The power control system of the wind turbine parameters values issued by the regulator for certain values of the wind and the angle the $\psi$ angle between the wind direction and the position of the nacelle.

2. It must be taken into account that the increasing and decreasing in air temperature, because it effects on the wind flow power.

3. Due to the rapid change in wind direction occur frequently fluctuation of the value of the pitch angle, the using of the PID - Regulator pitch angle of the blade is changed in a small range.

4. From the simulation program, it can be concluded that the wind turbine capacity of more than $200 \mathrm{~kW}$ corner nacelle rotation speed is limited to a value of $0.1 \mathrm{rad} / \mathrm{s}$. and blade rotation is limited to $5-8 \%$.

5. Theoretically and by calculation proved the possibility of effective regulation of the power of large wind turbine controller fuzzy type, functioning on the basis of production rules " if - then ".

\section{Notation}

$\mathrm{p}_{\mathrm{p}} \quad$ Generated power output

$\mathrm{Cp} \quad$ Power Coefficient is the ratio of power extracted by the turbine to the total contained in the wind resource is taken equal to 0.4

$\rho$

A swept area of the wind wheel (m)

$\mathrm{V}$ the velocity of the wind

$\mathrm{Z} \quad$ rapidity, one of the main parameters

that characterize the wind turbines for «Vestas» is taken equal to 4.2

$\alpha \quad$ Pitch angle ( blade angle of attack)

$\psi \quad$ angle of misalignment between the position of the nacelle and the prevailing wind direction, $\mathrm{d} \psi$ ( change in its value)

$\beta \quad$ Nacelle angle

$\mathrm{L}_{\text {blade }} \quad$ the blade length, $\mathrm{dL}$ ( change in its value)

$\mathrm{n} \quad$ rotation frequency

$\omega$ the angular velocity

$\mathrm{M}_{\mathrm{p}} \quad$ the relative moment

$\mathrm{N}$ working speed, corresponding to the second area of operation of wind turbines

$\mathrm{H}$ high speed, corresponding to the beginning of the third wind turbine work area

$\mathrm{VH}$ a very high rate, corresponding to the end of the third working zone wind turbines

$\mathrm{Cr} \quad$ critical speed corresponding to the request shutdown of wind turbines because of the high aerodynamic loads.

$\mathrm{Z} \quad$ zero value

M the mean value

D great value

$\mathrm{N}$ normal value

NL negative large change

NS a small negative change

PS positive small change

PL positive large change

$\mathrm{r}$ the minimum blade length

$\mathrm{R}$ the maximum blade length 


\section{References}

[1]GWEC. Global Wind Statistics (2015) . www.gwec.net/, 2015 .

[2] Luis Arturo Soriano, Wen $\mathrm{Yu}$, and Jose de Jesus Rubio "Modeling and Control of Wind Turbine", Mathematical Problems in Engineering Volume 2013 (2013), Article ID 982597, 13 pages, 2013.

[3]Zafer Civelek, etc," Control of Pitch Angle of Wind Turbine by Fuzzy Pid Controller", Taylor \& Francis Online. http://www.tandfonline.com/page/models-anddates-explained, 2015.

[4]PIAO HAIGUO and WANG ZHIXIN "Simulation Research of Fuzzy-PID Synthesis Yaw Vector Control System of Wind Turbine", WSEAS TRANSACTIONS on SYSTEMS and CONTROL, Department of Electrical Engineering Shanghai Jiaotong University No.800 Dong Chuan Road, Shanghai 200240, CHINA, 2007.

[5] Stefanos Theodoropoulos, Dionisis Kandris, Maria Samarakou, and Grigorios Koulouras" Fuzzy Regulator Design for Wind Turbine Yaw Control" , The Scientific World Journal Volume (2014), Article ID 516394, 9 pages, 2014.

[6] [6] Vineet KUMAR, B. C. NAKRA and A. P. MITTAL " A Review on Classical and Fuzzy PID Controllers “,INTERNATIONAL JOURNAL OF INTELLIGENT CONTROL AND SYSTEMS ,VOL.16,NO.3,September/December,170-181, 2011.

[7]Mr. Vinay Barod, Ms. Shalini Modi," Comparison of MAMDANI \& SUGENO type fuzzy inference system on enrollment datasets", International Journal of Engineering Sciences \& Research Technology, India, May, 2016

[8] Srivani S. G. ," Harmonic Reduction in Wind Energy Systems Using FLC and PI based Shunt Active Filter", Proceedings of the World Congress on Engineering 2016 Vol I WCE 2016, June 29 - July 1, London, U.K, 2016.
[9]Enrico De Santis, Alireza Sadeghianz, and Antonello Rizzix," A Hierarchical Genetic Optimization of a Fuzzy Logic System for Flow Control in Micro Grids",Dept. of Information Engineering, Electronics, and Telecommunications, University of Rome, Italy,2016.

[10] Omar Adil M. Ali, Aous Y. Ali, Balasem Salem Sumait, "Comparison between the Effects of Different Types of Membership Functions on Fuzzy Logic Controller Performance", International Journal of Emerging Engineering Research and Technology Volume 3, Issue 3, PP 76-83, March 2015

[11] Mohammed Sabeeh Kadhim, Mr. Ch. Ravi Kumar," Load Frequency Control Using PID and Fuzzy Logic Control for Multi Area Interconnection System", International Journal of innovative research in Electrical, Electronics, Instrumentation and control engineering Vol. 4, Issue 7, July 2016

[12] The wind power, wind engineering market intelligence http://www.thewindpower.net/turbine_en_20 8_vestas_225.php

[13] Sumeet Kumar Gupta, Tanuja Kashyap," Improvisation of Power in Variable Speed Wind Turbine DFIG Modeal with Adaptive Network Based Fuzzy Logic Controller", International Journal of Advanced Research in Electrical,Electronics and Instrumentation Engineering, Vol. 5, Issue 3, March 2016.

[14] J. F. Manwell, J. G. McGowan, and A. L. Rogers, Wind Energy Explained: Theory, Design and Application. Wiley, 2009.

[15] P.N. Paraskevopoulos," Modern Control Engineering", book, CRC Press, 367-673pp ,736 pages, 2001.

[16] Peter Buba Zirra, Timothy Umar Maigari and Wallace Ebinum Ossai," A Fuzzy Based System for Determining the Severity Level of Osteomyelitis", International Journal of Advanced Research in Computer Science and Software Engineering, Volume 6, Issue 6, June 2016. 


\section{نموذج محاكاة لنظام سيطرة على قدرة توربينات الرياح مع منظمات ضبابية بواسطة خوارزمية ممداني ولارسن}

\section{غاده عادل عزيز الكيز}

قسم الهندسة الكهروميكانيكية/ الجامعة التكنولوجية عزدون

البريد الالكتروني: ghadasama@yahoo.com

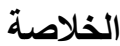

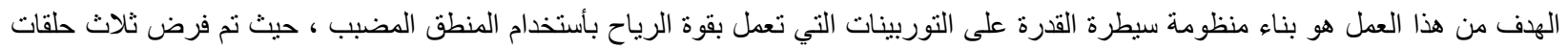



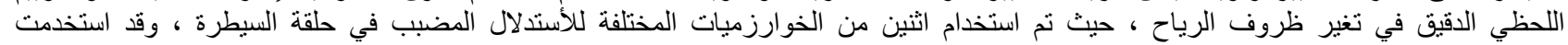

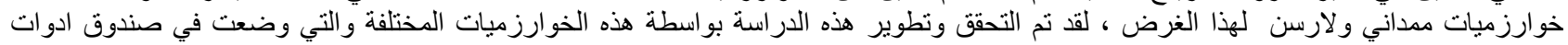

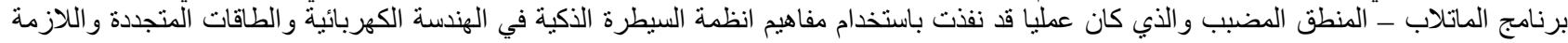
للتطبيق في البرنامج.

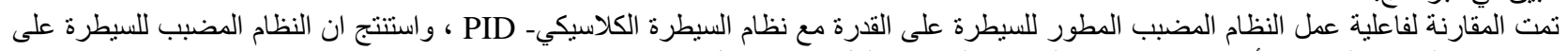

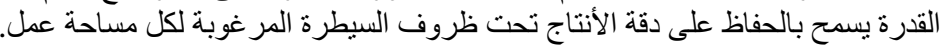

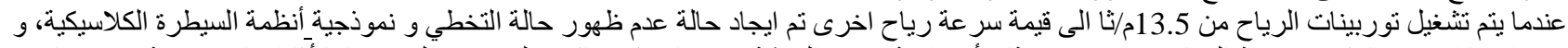

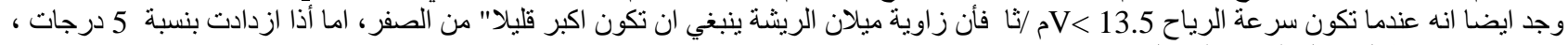

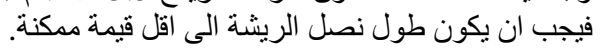

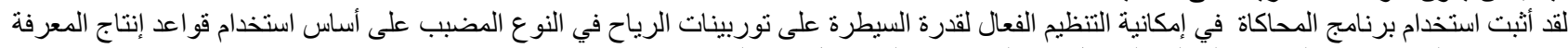
"إذا - ثم" و التي اظهرت السيطرة الفعالة على مثل هذه التوربينات التهان التي تعمل بقوة الرياح. 